Rock Valley Direct Earthquake-Explosion Comparison Experiment (RV-DC): Initial Feasibility Study

W. R. Walter, M. L. Pyle, S. R. Ford, S. C. Myers, K. D. Smith, C. Snelson, V. Chipman

September 27, 2012 
This document was prepared as an account of work sponsored by an agency of the United States government. Neither the United States government nor Lawrence Livermore National Security, LLC, nor any of their employees makes any warranty, expressed or implied, or assumes any legal liability or responsibility for the accuracy, completeness, or usefulness of any information, apparatus, product, or process disclosed, or represents that its use would not infringe privately owned rights. Reference herein to any specific commercial product, process, or service by trade name, trademark, manufacturer, or otherwise does not necessarily constitute or imply its endorsement, recommendation, or favoring by the United States government or Lawrence Livermore National Security, LLC. The views and opinions of authors expressed herein do not necessarily state or reflect those of the United States government or Lawrence Livermore National Security, LLC, and shall not be used for advertising or product endorsement purposes.

This work performed under the auspices of the U.S. Department of Energy by Lawrence Livermore National Laboratory under Contract DE-AC52-07NA27344. 
NCNS C2010

\title{
Rock Valley Direct Earthquake-Explosion Comparison Experiment (RV-DC): Initial Feasibility Study
}

\author{
William R. Walter ${ }^{1}$, Moira L. Pyle ${ }^{1}$, Sean R. Ford ${ }^{1}$, Stephen C. Myers ${ }^{1}$, \\ Kenneth D. Smith ${ }^{2}$, Catherine Snelson ${ }^{3}$ and Veraun Chipman ${ }^{3}$ \\ Lawrence Livermore National Laboratory ${ }^{1}$ \\ Nevada Seismological Laboratory, University of Nevada, Reno ${ }^{2}$ \\ National Security Technologies ${ }^{3}$
}

September 28, 2012 


\section{Executive Summary}

The RV-DC is designed to be the capstone of the ongoing Source Physics Experiments. This report describes the motivation behind the RV-DC and the tremendous potential scientific payoff for both nuclear explosion monitoring and earthquake source physics expected from the RV-DC experiment. The report describes the issues, work to date and plans for FY13 in the areas of defining the shot location, depth and size, as well as addressing potential concerns about induced seismicity. We believe the RV-DC is feasible. There do not appear to be any significant technical or scientific issues that would prevent the RV-DC from being carried out in the approximately FY14-16 timeframe. This timeframe allows sufficient time for work to continue in FY13 to better define the experimental plan. It is our recommendation, based on the work to date and the potential payoff of the RV-DC experiment, that the currently defined work for FY13 to better define the experimental plan, proceed.

\section{Table of Contents}

Overview and Key Science Questions to be Addressed .................................. 3

Defining the Drilling Target and Depth .................................................... 8

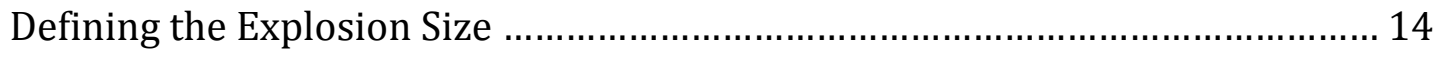

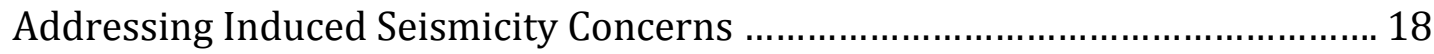

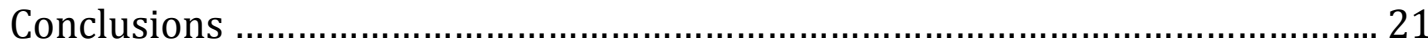

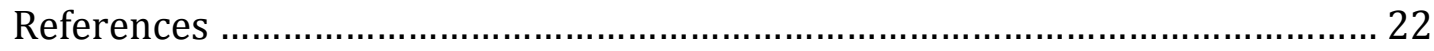




\section{Overview and Key Science Questions to be Addressed}

Underground nuclear test monitoring relies on seismic methods to distinguish between the explosions of interest and the abundant background signals that must be examined and discarded. Earthquakes are the most numerous of these and dominate the 43,460 events located and reported in just the year 2011 Reviewed Event Bulletin produced by the CTBTO (Comprehensive nuclear-Test-Ban Treaty Organization). Current methods of discrimination between earthquakes and explosions were derived empirically, and while effective at known test sites (Figure 1), lack solid physics-based models to predict their behavior in new regions or under new emplacement conditions beyond where we have empirical data.

The ongoing Source Physics Experiments (SPE) provides key development and validation data for small explosions ( $\leq 5$ tons) at shallow depths $(\leq 110 \mathrm{~m})$. The SPE is also providing earthquake data from the natural background seismicity, though the earthquakes are located at different depths and epicenters than the SPE explosions, necessitating imperfect corrections to compare them. The most direct examination of the seismic differences between the two source types would be to detonate a similarly sized explosion at the location of a previous earthquake.

The Rock Valley Direct Earthquake-Explosion Comparison (RV-DC) Experiment proposes exactly that: to drill to the hypocenter of a previous earthquake and detonate a large chemical explosion. This is possible at the Nevada National Security Site (NNSS) because of the region of unusually shallow earthquakes in Rock Valley in area 27 (Figure 1). In May 1993 there were eleven earthquakes greater than magnitude 2, which were well recorded at regional distances (Figure 2) and were well constrained by UNR temporary seismic stations to be between 1 and $2 \mathrm{~km}$ deep.

These unusually shallow earthquakes do not discriminate from NNSS nuclear tests as well as earthquakes at more typical depths (Figure 3). Similarly we have observed some deep and extremely over-buried nuclear explosions such as certain Soviet peaceful nuclear explosions (PNE) also do not discriminate well at typical monitoring frequencies (Figure 4). The RV-DC will directly test these properties of shallow earthquakes and deep explosions providing crucial new data to improve our best models of these sources.

The RV-DC will be the first-ever direct comparison of co-located earthquake and explosion sources recorded at the same seismic stations. The RV-DC will be the capstone of the Source Physics Experiments (SPE) providing key development and validation data for testing models now being developed from SPE data and building new physics-based models for use in worldwide nuclear test monitoring. As an additional benefit, the RV-DC experiment will provide a rare direct sample of an earthquake source, allowing the determination of fault properties and shedding new light on the physics of earthquakes (Figure 5). 


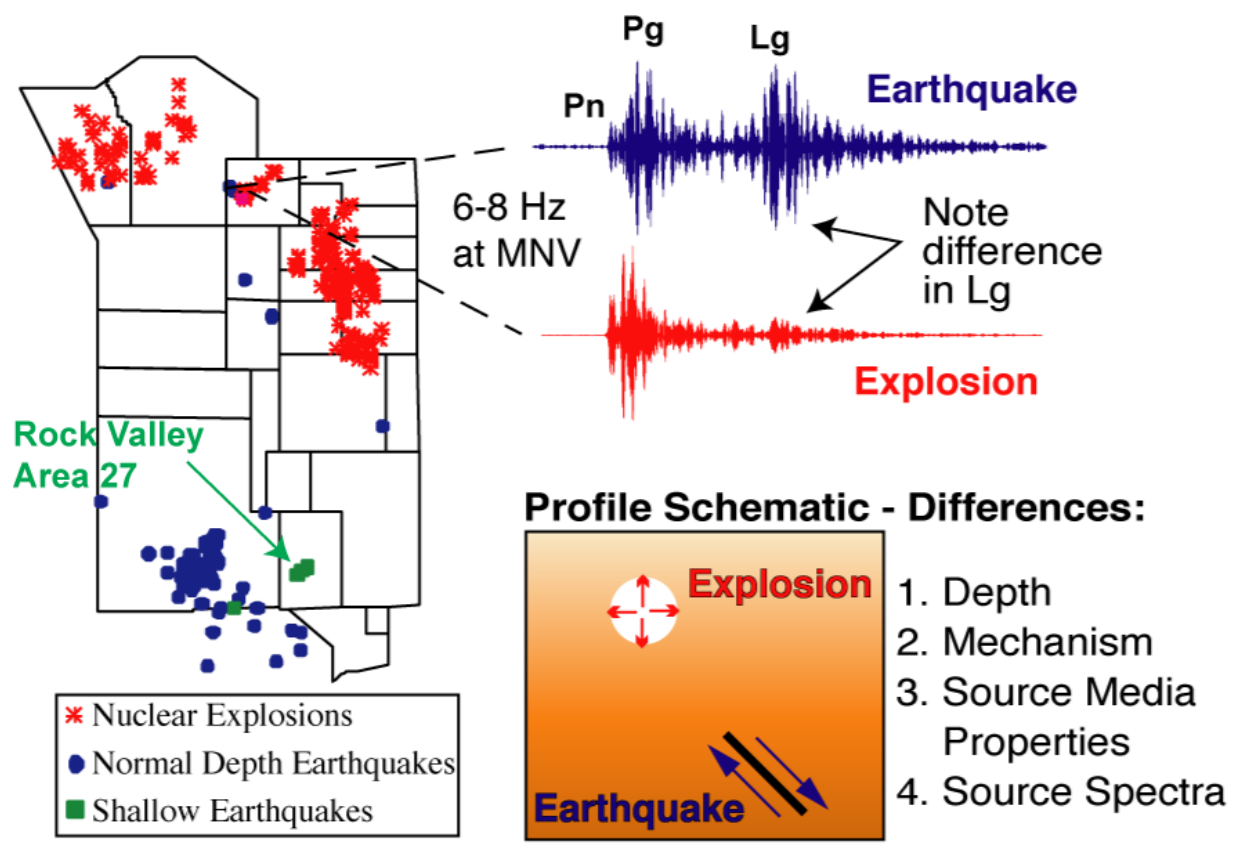

Figure 1. An overview map for some of the differences between earthquakes and explosions. The map on the left shows the NNSS with the locations of past nuclear tests, normal depth earthquakes and the shallow Rock Valley earthquakes. The observed differences in high-frequency Pn-Pg to Lg seismic amplitudes used to discriminate explosions from earthquakes are thought to be due to differences in depth and other properties. The RV-DC will provide the first direct comparison of these two types of sources at the same depth and source media properties.
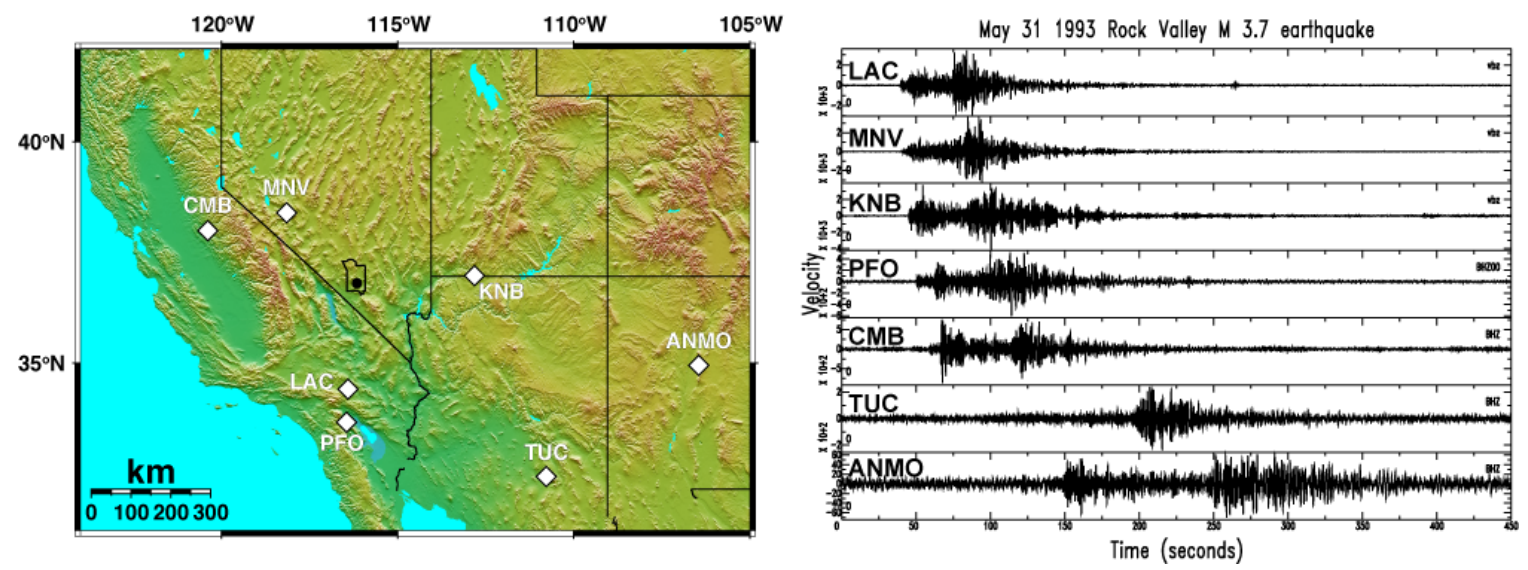

Figure 2. The 1993 Rock Valley Mw 3.7 earthquake and its larger aftershocks were well recorded at seismic stations throughout the western U.S. The RV-DC explosion will be recorded at these same stations for comparison with the 1993 sequence, other earthquakes and historic nuclear tests. 


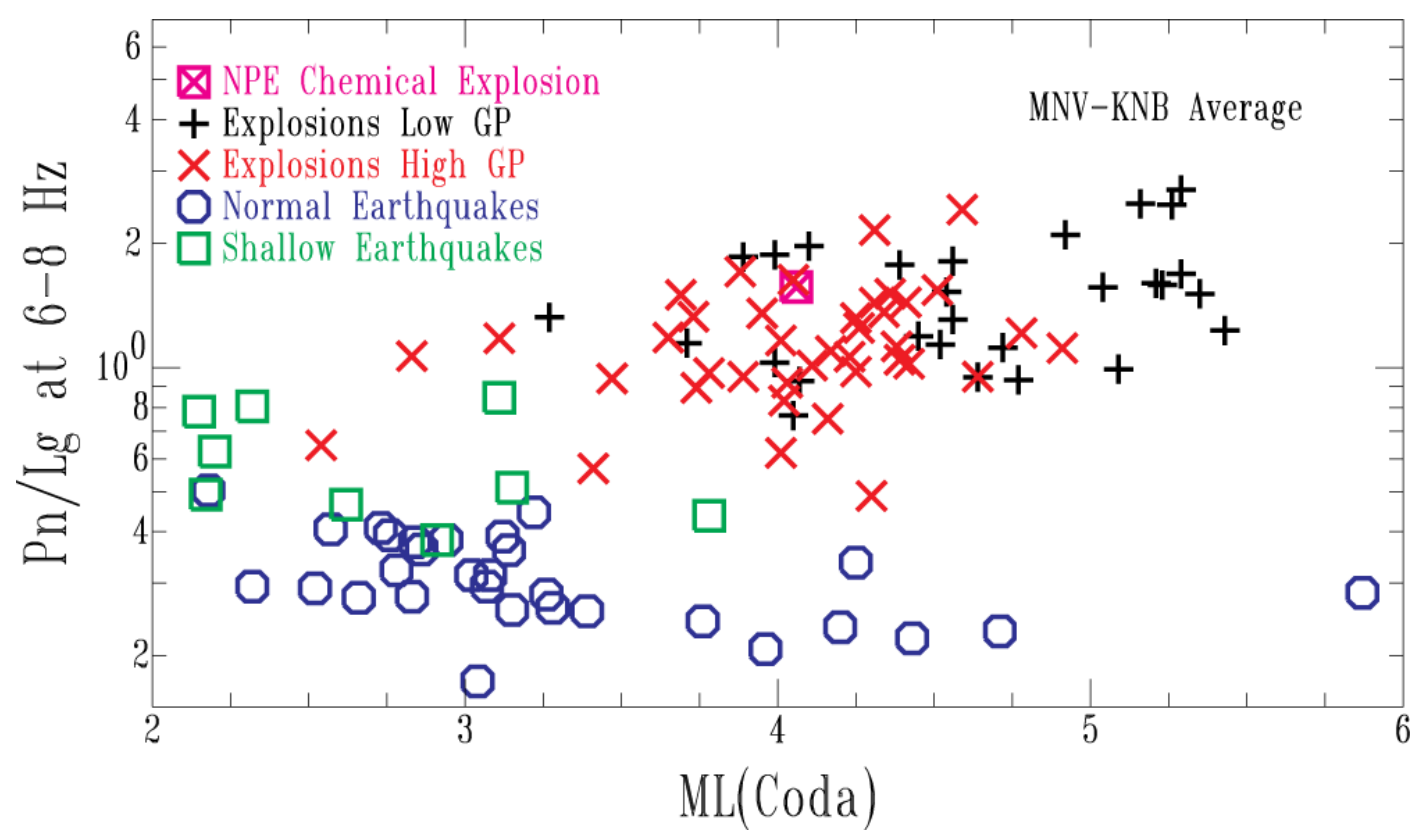

Figure 3. The shallow Rock Valley earthquakes (green) do not separate from the nuclear explosions (red and black - differentiated by the gas porosity) as well as the normal depth earthquakes (5-15 km) using two-station, MNV and KNB, average 6-8 $\mathrm{Hz} \mathrm{Pn} / \mathrm{Lg}$ ratios as a function of magnitude (after Walter et al., 1995). The RV-DC experiment will address the physics behind this behavior.
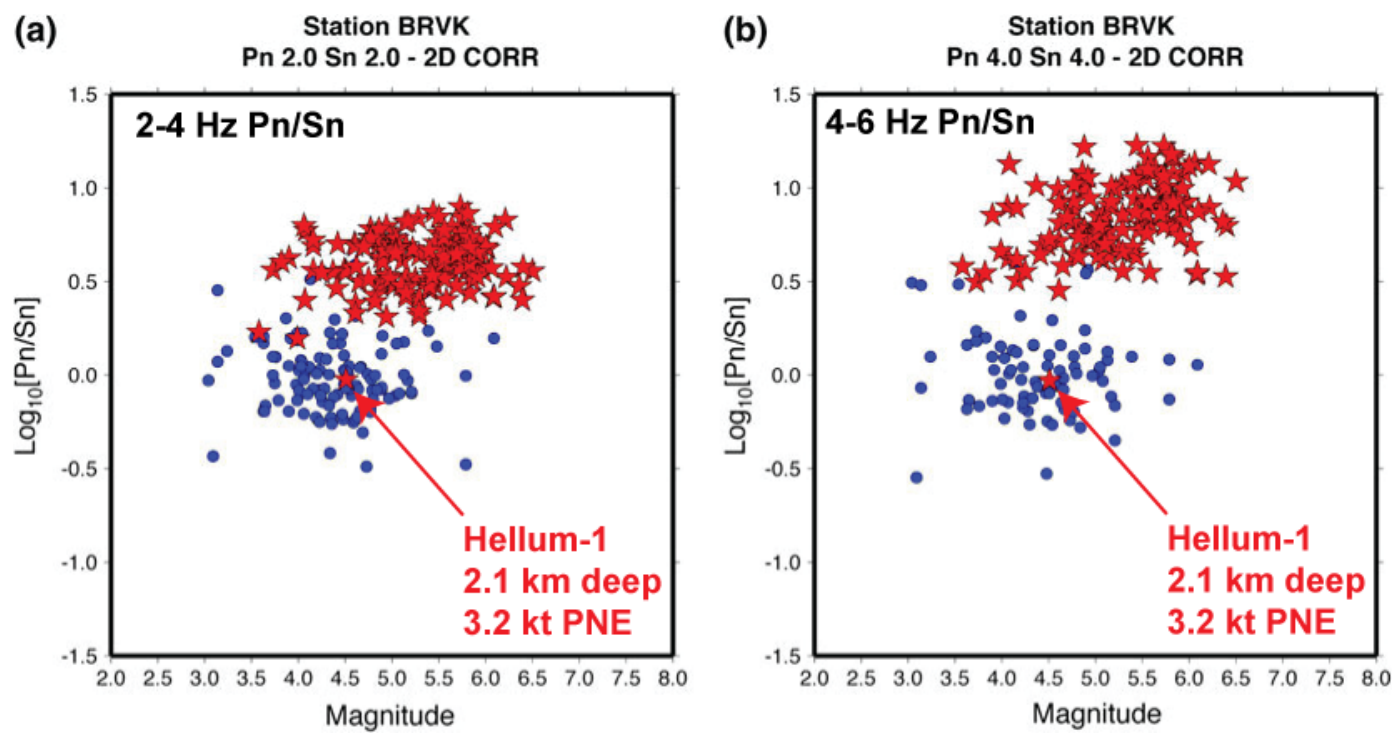

Figure 4. A number of deep nuclear explosions such as the 1981 Soviet PNE Hellum1 do not discriminate well from normal depth earthquakes at frequencies usually used for monitoring. Shown Soviet nuclear tests (red stars) and earthquakes (blue circles) recorded at station BRVK in present day Kazakhstan with the deep PNE called out (after Pasyanos et al., 2012). The RV-DC experiment will provide a similarly deep and over buried explosion to compare with past NNSS nuclear tests to address the physics behind this behavior. 


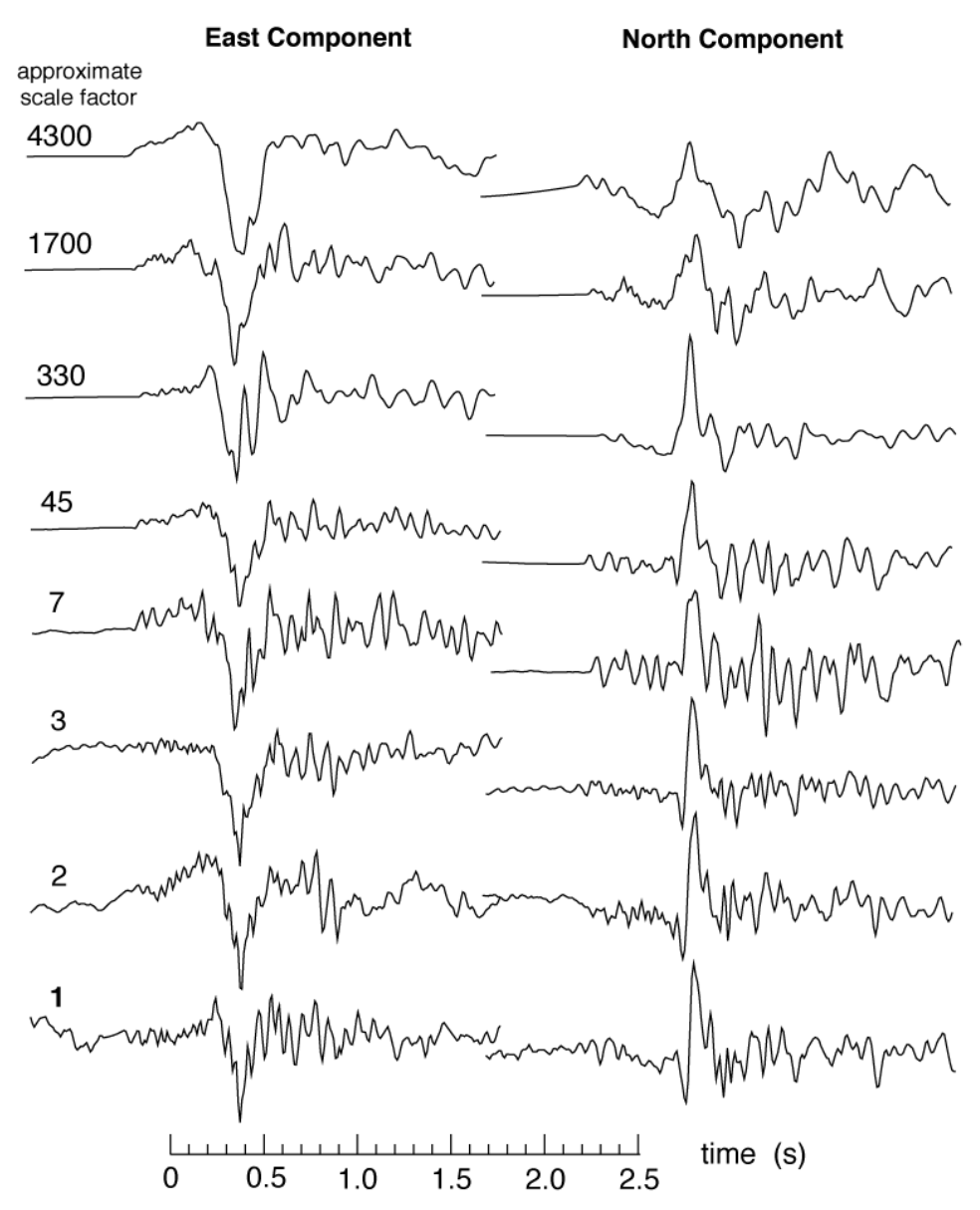

Figure 5. The RV-DC will also shed light on earthquake source physics. As an example reproduced from Shields 1999, are eight very different sized Rock Valley events recorded on the same station. The amplitude is given on the left and differs by two and a half orders of magnitude, but the S-wave pulse widths are remarkably similar. Shields (1999) did a lot of work to answer the questions of whether this similarity was a source property or due to a very attenuative material in the 1-2 km above the source or even a non-linear response of the soil or the seismometer and was not able to come to a definitive conclusion. Shields (1999) best estimates for the source parameters show that all the events have remarkably high apparent stress drops averaging around 100 bars and ranging between 10 and 500 bars. He notes that the results depend upon attenuation estimates, if his attenuation estimates are too high then the stress drops could be lower but with the result that then the sequence would show a strong variability of stress drop with size indicating non-self-similarity. The question of whether earthquakes are self-similar is an active area of investigations (e.g., Walter et al., 2006). The RV-DC will be able to address and answer the question of attenuation above the Rock Valley source and the stress levels of earthquakes in the source region. 
Key scientific questions to be addressed by the RV-DC experiment:

1) What are the fundamental differences between the seismic waves generated by an explosion and an earthquake at the same location and with the same media properties (e.g., radiation pattern, moment tensor mechanism, seismic spectral amplitudes for each phase, stress levels, damage effects, etc.)?

2) What changes are needed to our physics-based explosion and earthquake models to match the RV-DC data?

3) How do we best exploit the earthquake/explosion differences to identify explosions and discriminate them from earthquakes in actual monitoring networks?

4) Do those RV-DC observed differences and improvements in our models resolve some of the confusing empirical data we have previously observed (e.g., poor discrimination of some deep explosions and shallow earthquakes; why Ms-mb does not work well for small magnitude events, etc.)?

5) What are the fault zone properties of the Rock Valley shallow and relatively young fault zone? Are the high apparent stress levels observed by Shields (1999) confirmed?

6) How do the Rock Valley fault parameters compare with the more mature and deeper seismicity observed at the San Andreas fault in the National Science Foundation Earthscope SAFOD project?

7) Can we use the improvements in our physics-based earthquake models from the RV-DC experiment to improve our understanding of earthquake scaling and hazard forecasting? 


\section{Defining the Drilling Target Location and Depth}

The locations of the 1993 Rock Valley earthquakes are well constrained, particularly in depth due to the deployment of temporary seismic stations by the University of Nevada, Reno (UNR) and the more permanent seismic network that was running at the time. The sequence is associated with the Rock Valley fault zone, a northeast striking left-lateral strike-slip near-vertical dipping fault zone that shows geologically recent displacement at the surface. For the RV-DC experiment we want to improve these locations for the sequence, pick one of the 12 largest earthquakes in the sequence to be the drilling target, and then make sure the hypocenter is known to within a few hundred meters or better before drilling commences.

We are working to improve the Rock Valley earthquake locations in three ways:

1) We installed new seismic instruments in 2011-2012 around the Rock Valley site to capture the ongoing very small seismic events on the active fault.

2) We are making plans to better characterize the surface trace of this fault via field observations and remote sensing (e.g., SAR and LIDAR) techniques.

3) We are using advanced new multiple event location techniques including the BayesLoc algorithm (e.g., Myers et al., 2007) and high precision crosscorrelation methods to improve on the already very good locations from Shields (1999) and Smith et al. (2000).

The 1993 sequence's largest events lie along the Rock Valley fault zone and have left-lateral mechanisms (Figure 6). The depths are very well constrained by a temporary station RTPP deployed by UNR nearly directly above the sequence. In Figure 7, the records from the third largest event are shown at the temporary station RTPP and the very short S-P time constrains the depth to be shallow. Smith et al. (2000) use a P-wave velocity of $3 \mathrm{~km} / \mathrm{s}$ and a S-wave velocity of $1.73 \mathrm{~km} / \mathrm{s}$ to get depth of 1-3 km for all the largest events and a hypocentral depth of $1.9 \mathrm{~km}$ for the largest event. Under a range of plausible velocities and Poisson ratios the depths of these events are shallow and must be less than 3-4 km. In Figure 8, the location of the events in a depth cross section is shown. The largest events are confined to depth between 1 and $2 \mathrm{~km}$ using the RTPP S-P time as control and assuming the Poisson ratio is near 0.25 . 


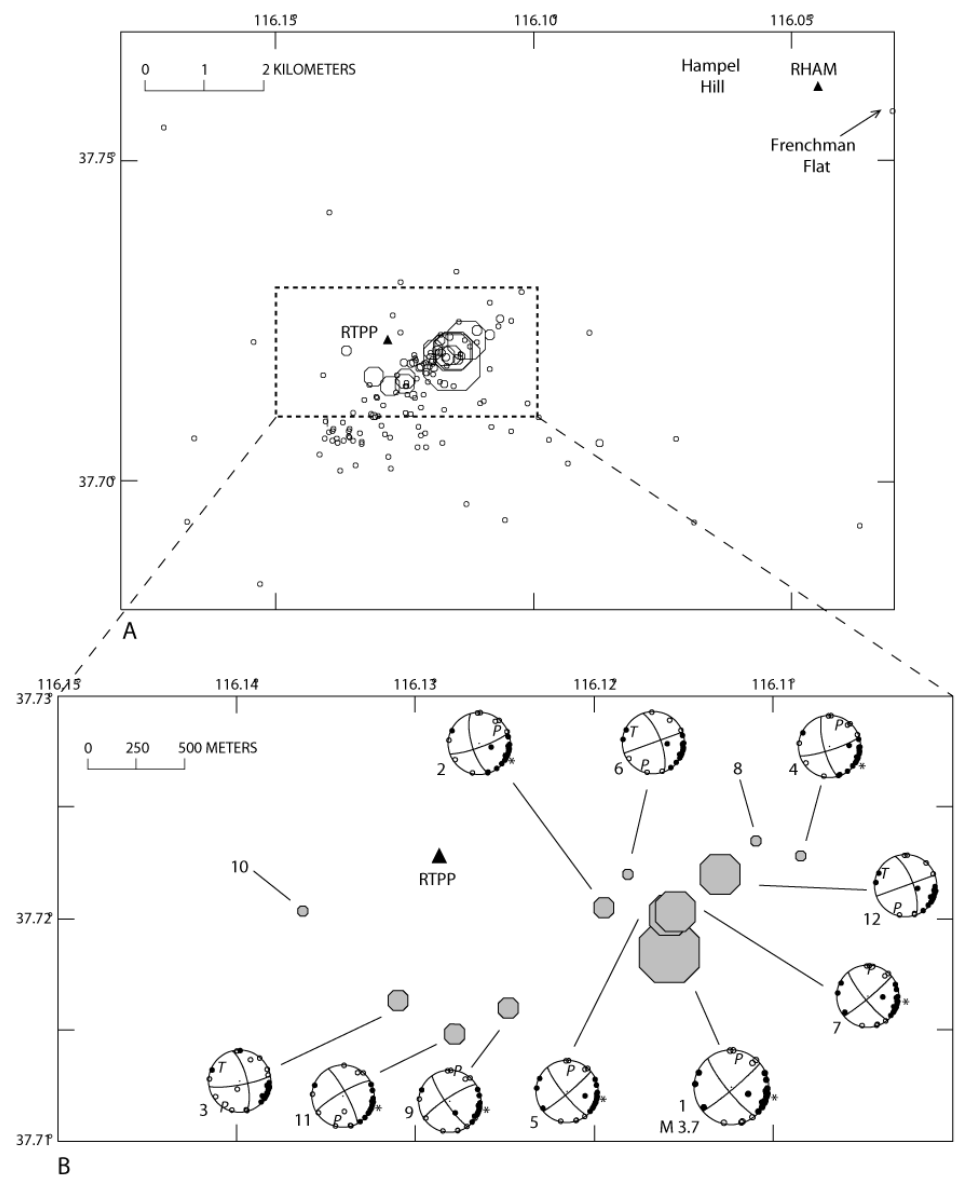

Figure 6. A) Relocation of 140 earthquakes of the sequence. B) Expanded view of part A showing P-wave first-motion focal mechanisms indicating left-lateral strike slip motion for the 10 largest events. The largest event is indicated with an Mw magnitude of 3.7 (from Smith et al., 2000).

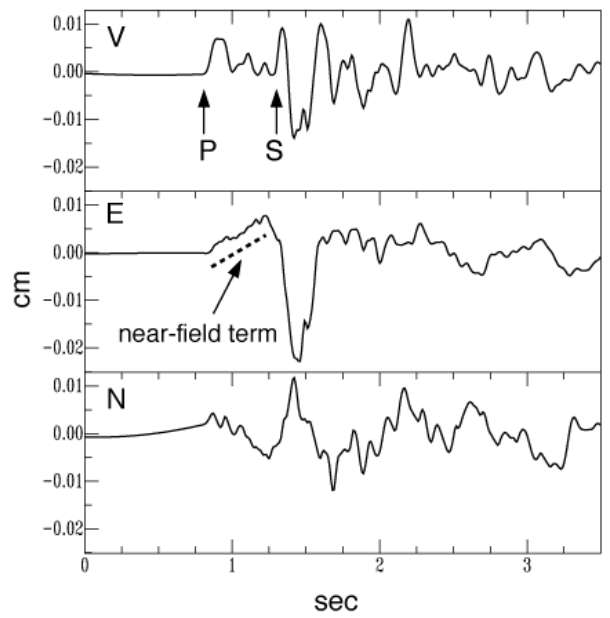

Figure 7. Data from station RTPP for the third largest event in the sequence showing the very short and well constrained time between the $\mathrm{P}$ and $\mathrm{S}$ wave arrival, $0.51 \mathrm{~s}$ for this event. Such short times indicate a very shallow depth (from Shields, 1999). 


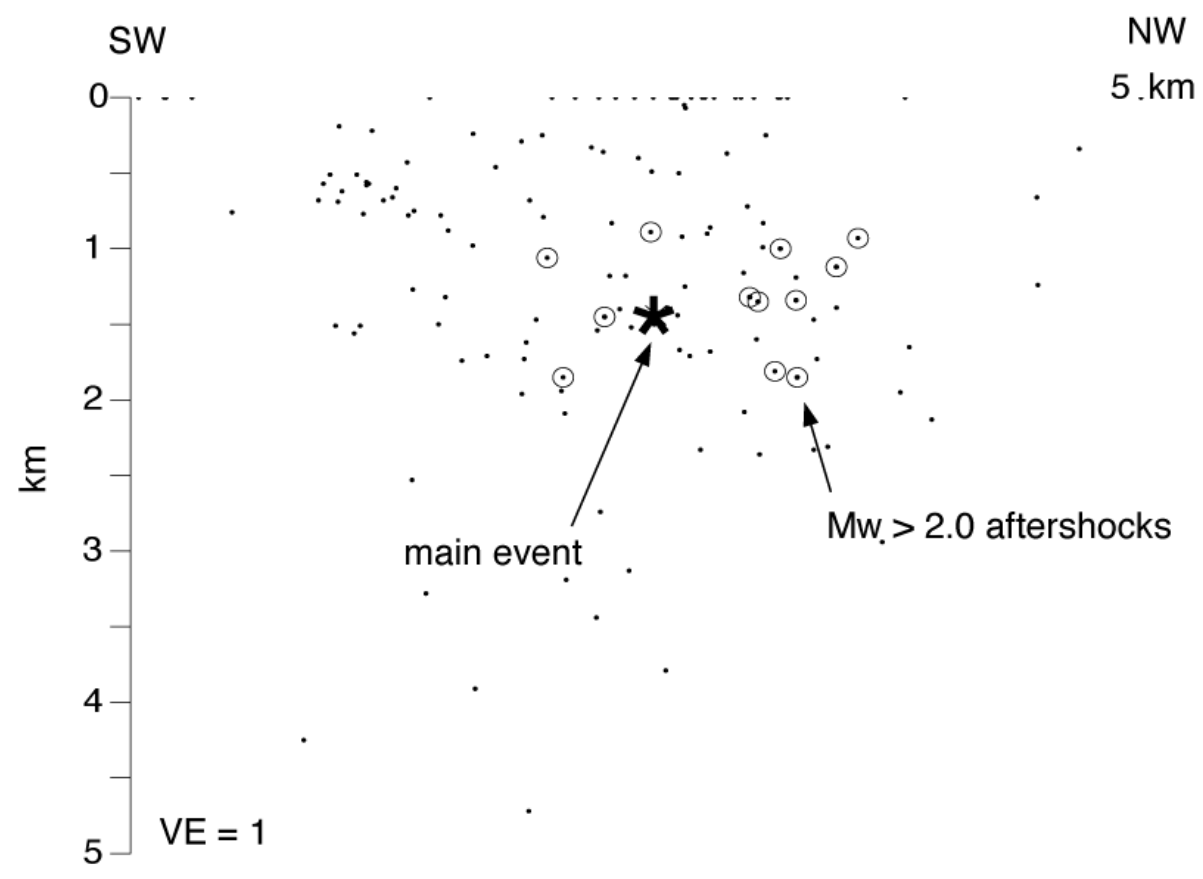

Figure 8. A depth cross-section showing the location of the largest or main event and the largest aftershocks. There is no vertical exaggeration (VE) in this figure (from Shields, 1999).

After 1993 the temporary station RTPP was removed and over the past several years the number of seismometers deployed in the more permanent Southern Great Basin Network was greatly reduced. In order to get high quality locations of the current small seismicity to help pin down the location of the active fault a new instrumentation plan was developed. In the Fall 2011 LLNL, UNR and NSTec personnel visited the Rock Valley region and finalized the plan and location for eight new three component telemetered seismic stations to record and constrain the depth and location of current seismicity. A number of these stations were deliberately sited to reoccupy sites that had recorded the 1993 sequence including the very important RTPP station. UNR staff installed six of these stations in the Fall 2011 and Winter 2012. In Figure 9 the location of these new stations is shown along with the 1993 seismic event locations.

On May 21, 2012 a very small, magnitude -0.4 earthquake was recorded on or near the Rock Valley fault. The seismograms from that event are shown in Figure 10. Note the very short S-P time on the reoccupied RTPP site. The new stations tightly constrain the location of this event and with the S-P time the depth is about $1.7 \mathrm{~km}$. This earthquake indicates the shallow Rock Valley fault is active and over the time period of the planning for the RV-DC experiment we expect to record a number of additional events to be used to help relocate all of the Rock Valley seismicity. 


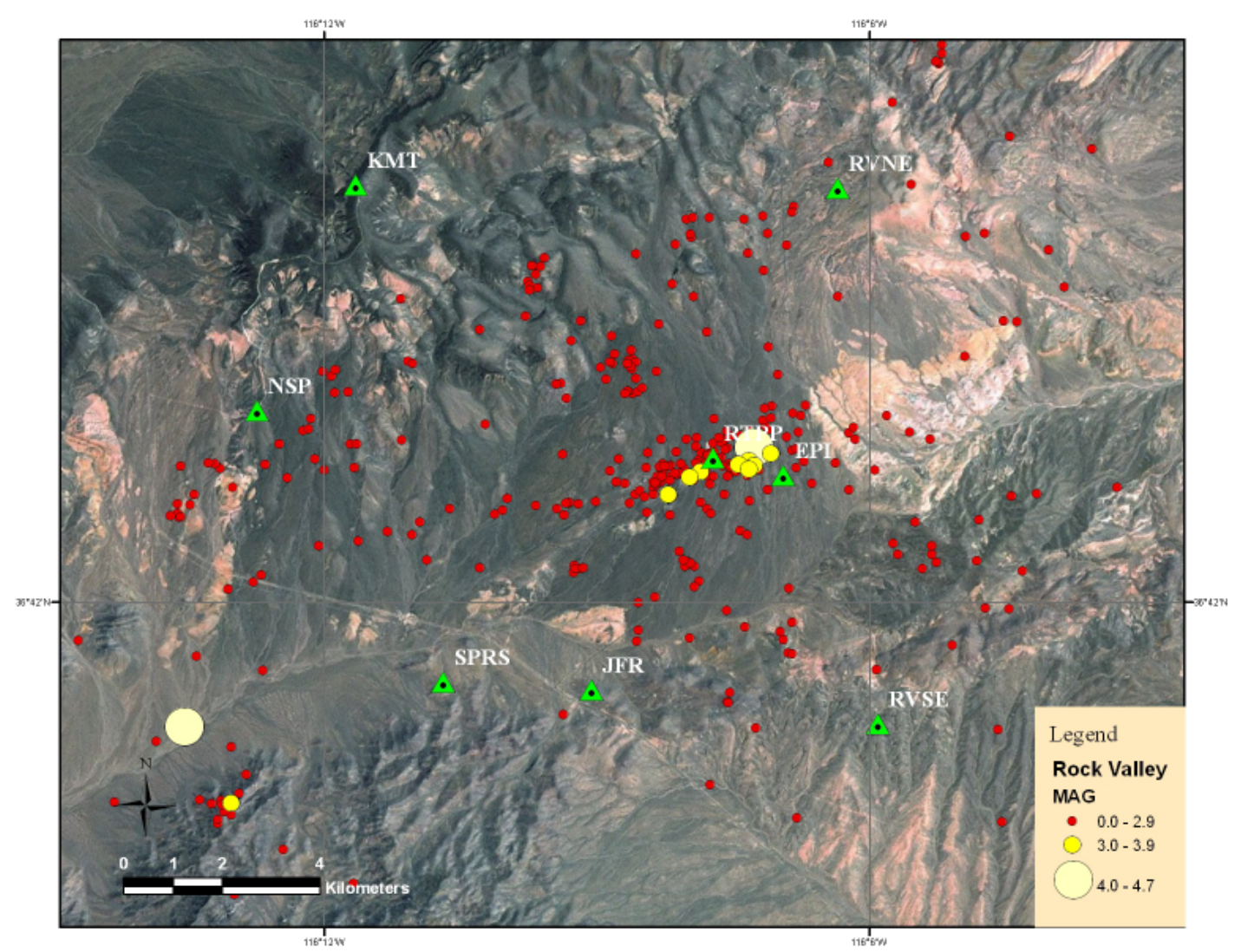

Figure 9. Map from UNR of the new station locations and historic seismicity. Event locations above are based on UNR permanent stations and catalog phase data; they do not yet include 1993 portable station phase arrival times.

In FY 13, we would hope to add one or two additional stations, one such as EPI to help in conjunction with RTPP to constrain the depths via S-P time. As stated in our instrumentation plan, if it were possible to create a small borehole or vault to get below some of the very low velocity sediments in this region, this could really help constrain the event depths even better. In addition, another station to the east of the current station locations would be very desirable to help close the azimuthal gap and better constrain the locations. 


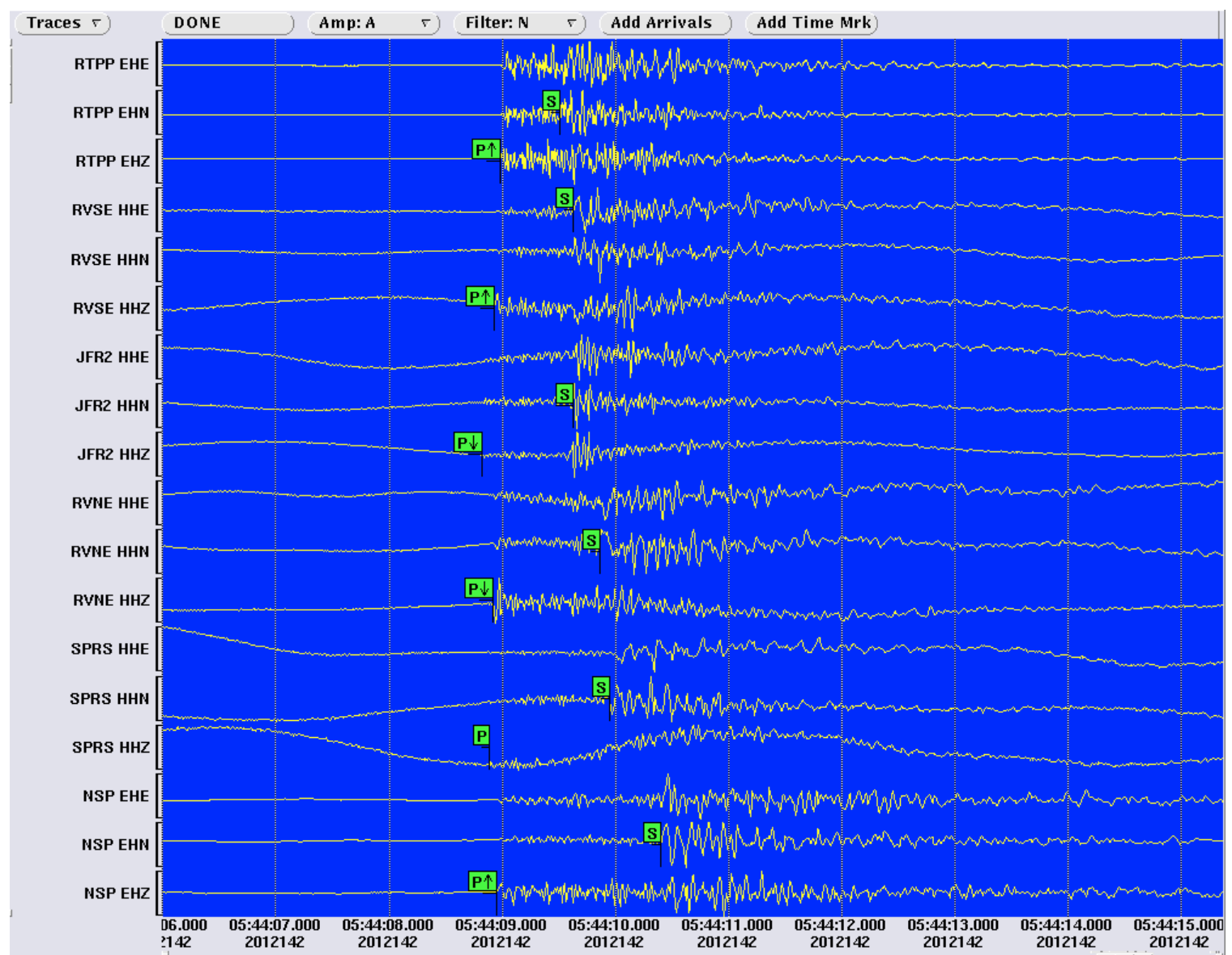

Figure 10. Screen picture from UNR of the seismograms from the May 21, 2012 Rock Valley magnitude -0.4 , depth $1.7 \mathrm{~km}$ earthquake. Note that despite its small size it is well recorded on all of the newly deployed seismic stations and shows the characteristic small S-P times of very shallow earthquakes.

Previous work by Shields (1999) and Smith et al. (2000) has done a very good job of refining the location of the 1993 Rock Valley sequence. However, new multiple event algorithms have been developed since then including the LLNL developed BayesLoc (e.g. Myers et al., 2007, 2009). These algorithms allow us to use so-called "ground truth" or GT0 events, that is events such as the historic nuclear tests whose location and depths are known exactly, as constraints in the location process. In addition, cross-correlation techniques allow the relative pick time between events to be used as a constraint. As a test of these techniques, we have started exploring the use of correlated regional Pn picks on the historic nuclear tests where we know the exact locations. In Figure 11, we show a test using 12 Pahute Mesa nuclear tests to the north as GT0 constraints in locating 12 Yucca flat nuclear tests whose locations are estimated. Using our current velocity model, we find locations are on average are determined to within 1100 meters and the depths to with 200 meters, which is an extremely good result for a regional sparse station location. We also note the locations are all biased to the south, which indicates that we may be able to fix the bias with a better velocity model and/or station corrections. 


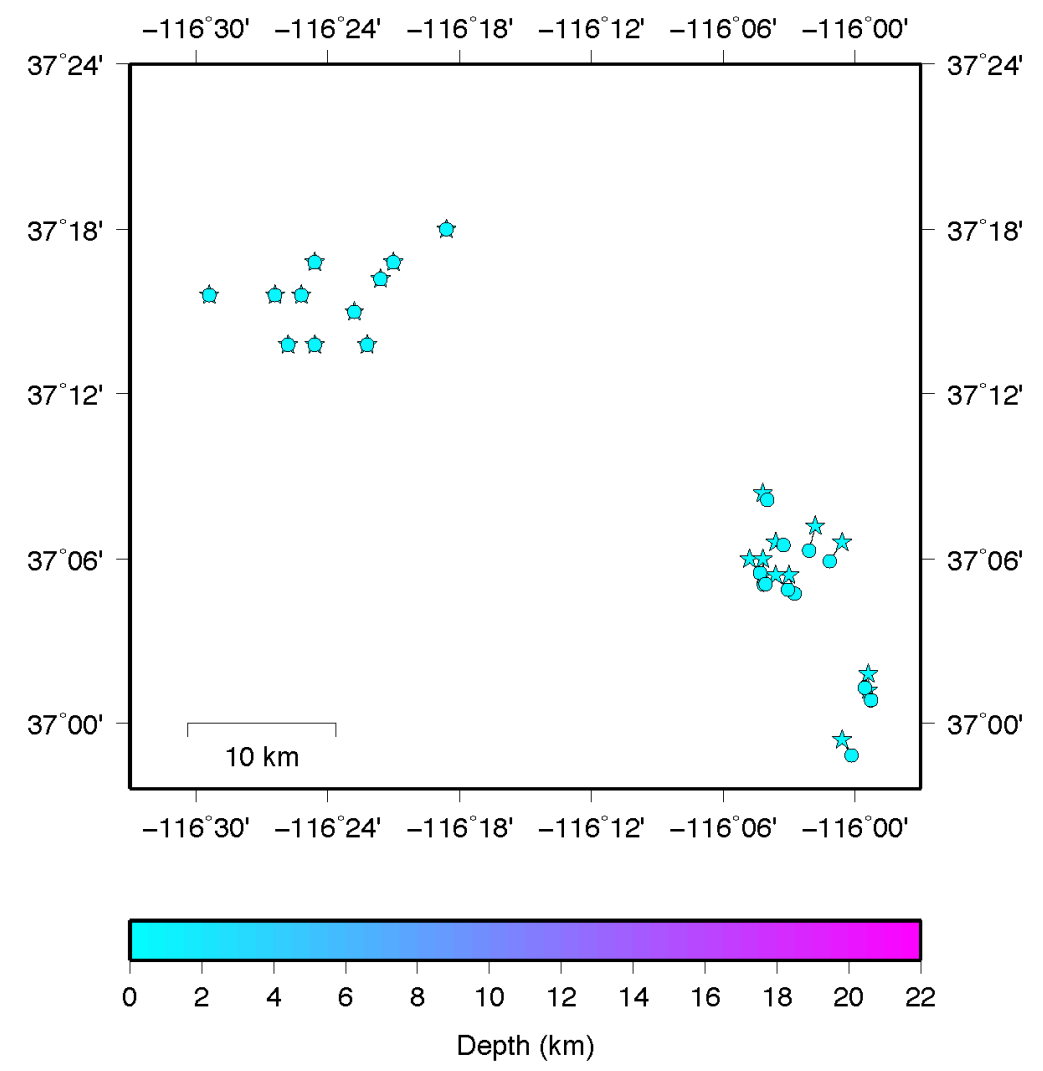

Figure 11. Map showing the location and depth (color of symbols) of the 12 Pahute Mesa nuclear tests used as GT0 known events and the 12 Yucca Flat nuclear tests to be located (stars). Using correlated regional Pn picks and the BayesLoc algorithm we find the estimated location for the Yucca Flat nuclear tests shown as circles.

For Rock Valley we can use all of the NNSS nuclear tests as GT0 constraints. We will also make use of the local station picks. Locations with such high precision local and regional data have not been conducted before using BayesLoc with correlated picks. Where possible we plan to test the results on the historic nuclear tests where results are known and then apply them to Rock Valley in FY13 as part of our lifecycle plan. We believe these new location techniques can provide the best possible seismic information to determine the drilling location and depth. Finally, we also plan to take advantage of the surface expression of the fault as an additional constraint.

Recommendations for next steps for FY13:

1) Work with UNR and NSTec to add one or more additional seismometers to help refine the depth and location of the ongoing seismic activity

2) Continue to apply BayesLoc and correlation techniques to regional and local data to determine the best possible locations of the Rock Valley events.

3) Based on size, depth, and data quality choose the target earthquake.

4) Work with UNR and NSTec to plan additional measures such as field observation or remote sensing techniques like SAR and LIDAR to better define the fault trace near the drilling target earthquake 


\section{Defining the Explosion Size}

A key factor in planning the RV-DC experiment is to determine the size of the explosion, which needs to be large enough to be seen seismically at regional distances $(\sim 200-1000 \mathrm{~km})$ over the frequency range of interest to monitoring $(\sim 0.5-16 \mathrm{~Hz})$. In terms of cost and experimental feasibility, we want to keep the explosion size as small as possible. In the current LCP we estimate the explosion size needs to be between approximately 10-50 tons. To refine this estimate we are proceeding in 3 ways:

1) Determining the seismic attenuation characteristics via tomography from the Rock Valley source to the local and regional seismic stations where we will compare the RV-DC explosion to the 1993 Rock Valley earthquake signals.

2) Using the results of the Phase 1 SPE series to test and update our best explosion models to improve our predictions for the RV-DC explosion

3) Compare explosion source characteristics from a straightforward high aspect ratio borehole shot to those from a more compact source using advanced technology to create void space at depth.

At LLNL, we have developed a new multiple phase seismic attenuation tomography method (Pasyanos et al., 2009). This technique uses existing earthquakes to map out attenuation as a function of seismic phase (e.g., Pn, Pg. Sn, Lg, and coda) and frequency, and then can straightforwardly be used to predict signal-to-noise for those same phases for an earthquake or explosion source (e.g., Pasyanos et al. $2012 \mathrm{~b}$ ). Work with high quality measurements of earthquakes at many stations throughout the western U.S. is well underway. In FY13, we expect to produce detailed local and regional attenuation maps for RV-DC scenario explosions. When combined with a refined explosion source model and a target earthquake location they will be a key part of defining the RV-DC shot size.

The SPE1, SPE2 and SPE3 results to date indicate our best empirical explosion source models: Mueller-Murphy (1971) and Denny-Johnson (1989) are not very good representations for over-buried explosions (those with scaled depths of burial much greater than $120 \mathrm{~m} / \mathrm{kt}^{1 / 3}$ ). The Denny-Johnson model comes closest to predicting the right amplitude levels for SPE1-3 but has too low of a corner frequency. The Muller-Murphy model comes closest to predicting the corner frequency but has too high amplitudes. The models do a better job of predicting the relative amplitudes between shots, so we can use them to roughly estimate the relative difference in expected amplitude for an RV-DC scenario explosion relative to the SPE shots. In Figure 12, we show predicted source moment rate spectra for the two models for a possible RV-DC 25 ton explosion at a depth of 1900 meters relative to the predictions for the SPE2 shot (a 1 ton explosion at $45 \mathrm{~m}$ depth). The predicted amplitudes are almost 5 times larger than SPE2 and likely would be sufficient to provide the desired signal-to-noise for the experiment. (Note that we 
have not made any adjustment for chemical/nuclear coupling differences here as we are using these imperfect models to predict relative amplitudes where such a scale factor cancels out. We also note the Denny -Johnson used chemical and nuclear explosions interchangeably whereas Mueller-Murphy was definined purely for nuclear tests. Adjustments to these models to work for both types of explosions is currently underway as part of our SPE related work).

Given the timeframe for RV-DC in FY14-16, we should wait to obtain results from SPE4 and SPE5 to better refine our explosion source model before finalizing the RVDC target explosion size. Nevertheless, the 10-50 ton range in our LCP for RV-DC seems very reasonable and we may well be able to reduce the shot size to 25 tons or lower as we refine the source and path models in FY13. Reducing the shot size is desirable for decreasing costs and simplifying logistics.

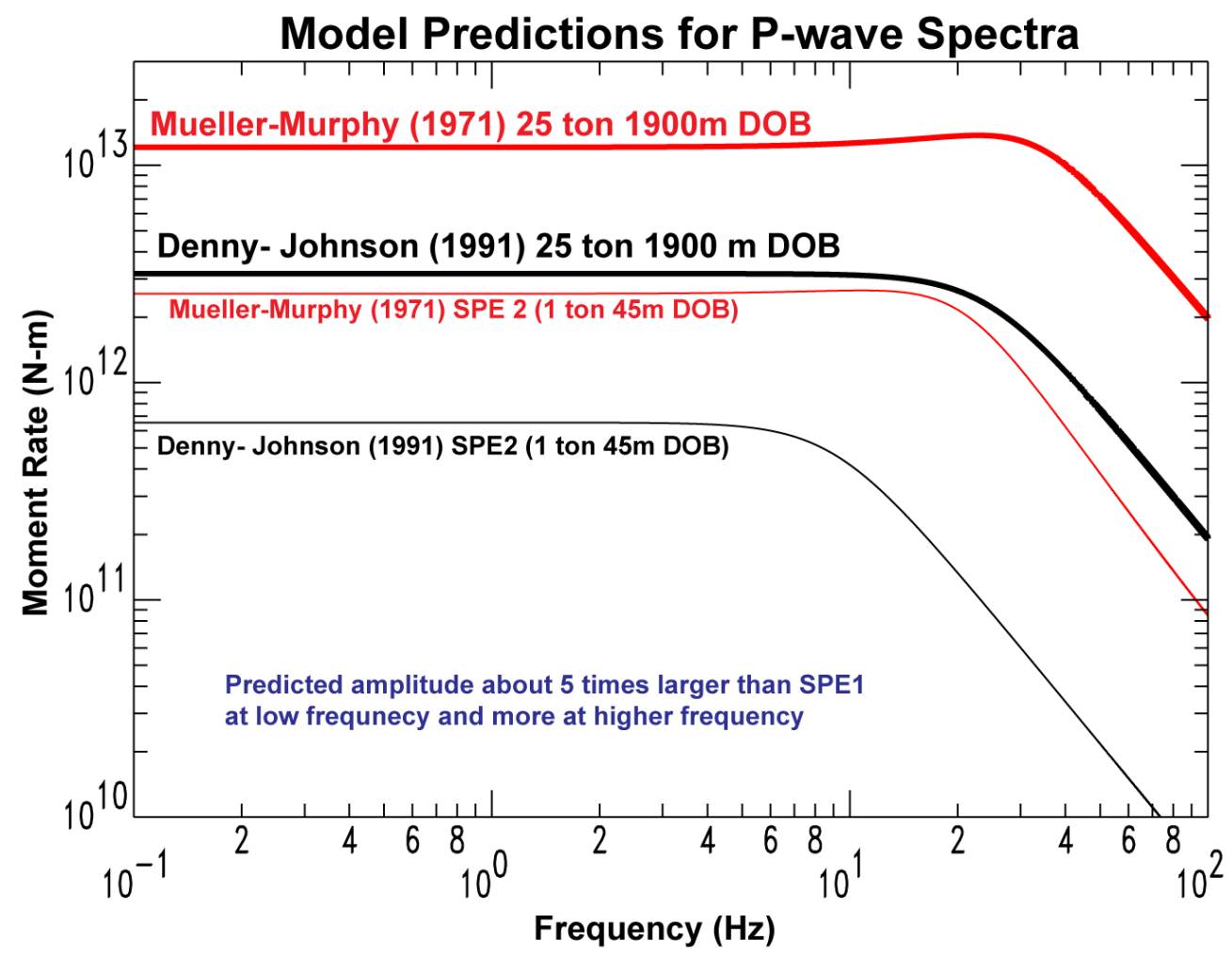

Figure 12. A preliminary prediction of a scenario 25 ton 1900 meter depth of burial RV-DC explosion compared with SPE2 predictions for two empirical models. SPE 2 was just barely observed at near regional distances. While both models have flaws that have been revealed by the SPE, they are useful to examine relative amplitude predictions. The SPE5 event in FY13-FY14 is expected to have amplitudes nearly 5 times larger than SPE2 and will provide a good empirical comparison point to these model calculations that also predict about a factor of 5 increase relative to the SPE2 shot. Once we have data from SPE5 that will help define the right size for the RV-DC explosion. 
Another aspect of the RV-DC explosion is the volume of chemical explosive needed. For the sensitized heavy ANFO (SHANFO) used in the SPE shots to date the density is approximately $1.29 \mathrm{~g} / \mathrm{cc}$ and the TNT equivalence in about 0.85 (Greg Dutro, ARA, pers. comm.). This leads to an estimate of about 0.83 cubic meter per ton of TNT equivalent yield. For a borehole similar to the SPE that is approximately 1 meter in diameter we need about 1.27 meters in length (depth) per ton of explosive yield. So for yield of 25 tons in a 1-meter diameter borehole we would need a length of about 32 meters.

While this is a fairly high aspect ratio explosion, for the seismic frequencies of interest, it may be similar enough to a more compact explosion to meet the RV-DC experimental needs. For the planned SPE5 5-ton explosion LLNL staff (Xu, Antoun and Lomov, written comm.) performed numerical calculations for a 9 meter long cylindrical explosion compared with a spherical explosion and showed that at distances greater than approximately 20 meters from the source, the ground motions were essentially identical. As part of the planned work in FY13, we will examine large aspect ratio comparisons suitable for the RV-DC experiment such as the $32 \mathrm{~m}$ to $1 \mathrm{~m}$ cylindrical explosion described above.

One area investigated in FY12 was whether advanced drilling technologies might be used to create void space at depth and thus allow smaller aspect ratio explosion configurations. For example, Potter Drilling Inc. has developed a spallation technique that can create voids in hard rock (Figure 13). They are developing this technique primarily for geothermal and other commercial applications. Potter Drilling provided a white paper in May 2012 to LLNL and NSTec that provided some details and a rough cost estimate for both SPE5 and the RV-DC experiment. Our conclusion at that time was that the costs and potential logistical issues precluded use of this technology for SPE5, relative to using a high aspect ratio explosion. Nevertheless, development work by Potter Drilling Inc. and other drilling companies continues and we plan to keep examining what is available in the years leading up to the RV-DC drilling and explosion. As the technologies mature, it is possible that costs may decrease and the logistics may improve to where we want to consider these technologies, particularly depending upon what we determine are the limitations on using high aspect ratio explosions as determined by the planned numerical simulations. 

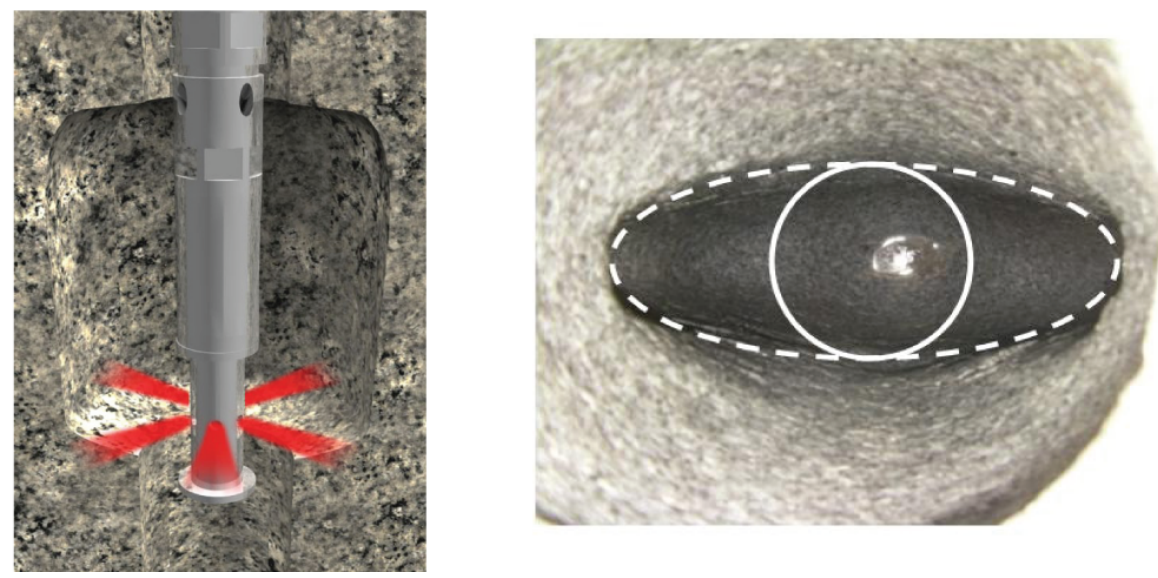

Figure 13. An example of an advanced technology to create voids at depth from Potter Drilling Inc. Left-hand side shows a graphic illustration of Potter's spallationbased hole opening tool. Right-hand side shows a double lobed slots (dashed lines) cut into Sierra White granite from an existing borehole (solid line).

Recommendations for next steps for FY13:

1) Continue work to create a seismic attenuation tomography model based on local and regional data. Use the model to predict expected signal to noise values from scenario RV-DC explosions for the phases and frequencies of interest.

2) Use the SPE results to refine the explosion source model for very over-buried explosions. Use the new model along with the seismic attenuation model to determine the needed explosion size at the target earthquake location and depth.

3) Run simulation calculations for large aspect ratio borehole shots compared to more compact shots. Confirm that a borehole shot will provide the desired compact explosion signals at the seismic frequencies of interest.

4) Keep abreast of ongoing developments in advanced drilling technologies and potentially re-assess their use if costs and logistics improve. 


\section{Addressing Potential Induced Seismicity Concerns}

Popular fictional entertainment has given the general public the incorrect impression that small explosions can easily trigger very large earthquakes. Indeed the plot lines of movies such as "Superman" (1978) and the James Bond film "A View to a Kill" (1985) center on the movie villain planning to trigger a major destructive earthquake on the San Andreas fault this way. While scientists understand that such ideas are the products of unscientific imagination, it is nevertheless important to provide a solid scientific basis for what the actual probability of explosion induced earthquakes are prior to conducting the RV-DC experiment. In doing this initial feasibility study we have addressed this concern scientifically in two ways:

1) We have examined the extensive record of nuclear testing at the NNSS and show that among hundreds of underground explosions up to the megaton level, none have ever triggered an earthquake with a seismic magnitude larger than the nuclear test.

2) For explosion monitoring purposes, we have developed a model for earthquake aftershocks due to explosions (Ford and Walter, 2010) and we have applied that model to the planned RV-DC experiment.

The NNSS contains hundreds of faults both active and inactive. From the start of nuclear testing underground in 1959 (RAINIER) until the most recent U.S. nuclear test (DIVIDER) in 1992, hundreds of explosions up to the megaton size were carried out at depths ranging from 0.2 to $1.5 \mathrm{~km}$ and magnitudes over 6 . We examined the seismicity catalog created for the Yucca Mountain Project (von Seggern and Brune, 2000) for aftershocks of the nuclear tests that were detonated within the timeframe of the catalog. Of the 119 explosions up to magnitude 6.5 covered in the catalog, none had an aftershock larger than the magnitude of the explosion itself, and only three had an aftershock within a half-magnitude unit smaller than the explosion itself. These results are shown in Figure 14.

For RV-DC we are considering a chemical explosion in the 10-50 ton range. Using Brocher (2003) and Kahturnin (1998), a 50-ton explosion would have a magnitude of about 3.7. These nuclear test empirical results suggest that any aftershocks or induced events are highly likely to have magnitudes of 3.7 or less and therefore not be threatening to property or people. 


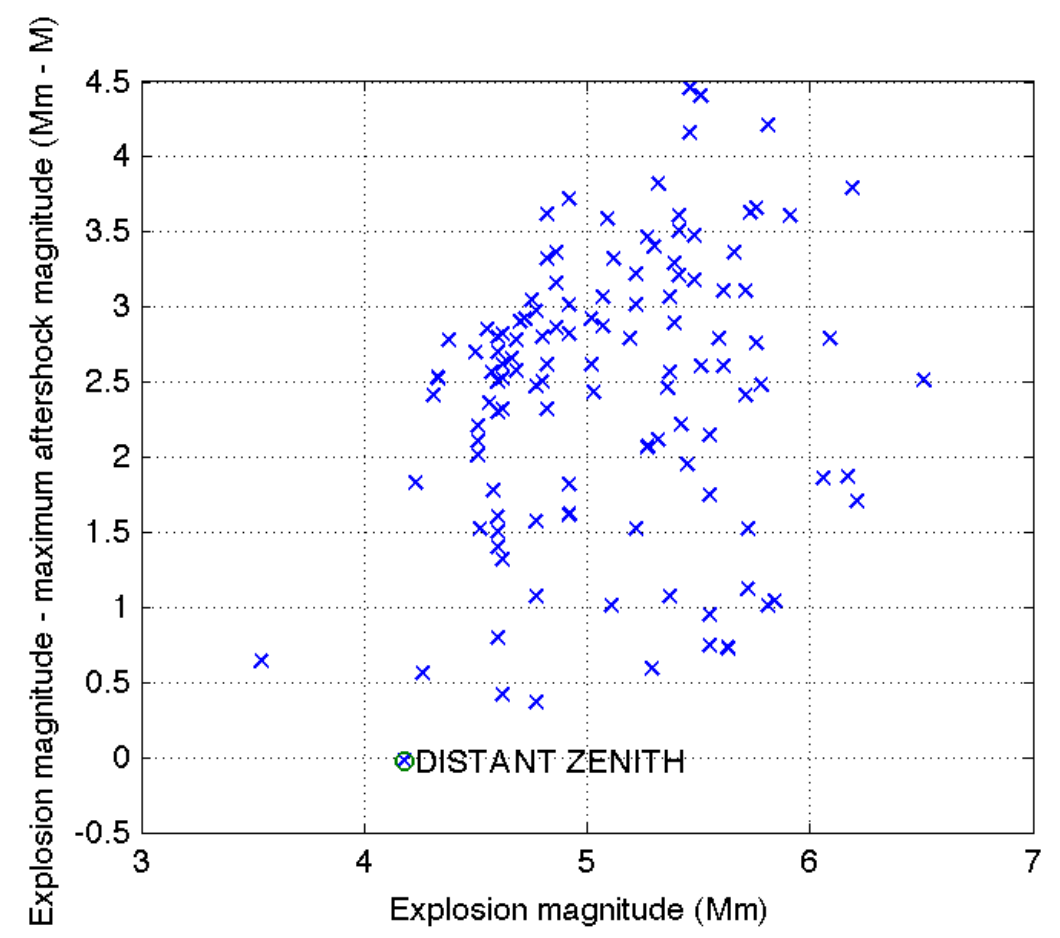

Figure 14. Explosion magnitude minus the maximum aftershock magnitude as a function of explosion magnitude for NNSS events. Note that none have induced event magnitudes greater than the explosion magnitude and only one event, DISTANT ZENITH has a magnitude the same as the explosion magnitude.

We also used our recently developed nuclear explosion aftershock model (Ford and Walter, 2010) to predict the probability of induced aftershocks for a magnitude 3.7 explosion. The results are shown in Figure 15 and confirm the probability of inducing an event greater than magnitude 4 is very low. As we are currently discovering in the SPE results, where we have not yet observed any aftershocks, these nuclear explosion models predict more aftershocks than chemical explosions actually induce. We also note that in 1997 three 25 -ton chemical explosions were done at the former Soviet Semipalitinsk test site as part of the Kazakh depth of burial experiment and did not induce any significant aftershocks (e.g., Myers et al., 1999). Therefore the results in Figure 15 likely overstate the already very small likelihood of inducing a larger aftershock from the chemical RV-DC. We plan to update our model in FY13 to better model the chemical explosion aftershock behavior. 


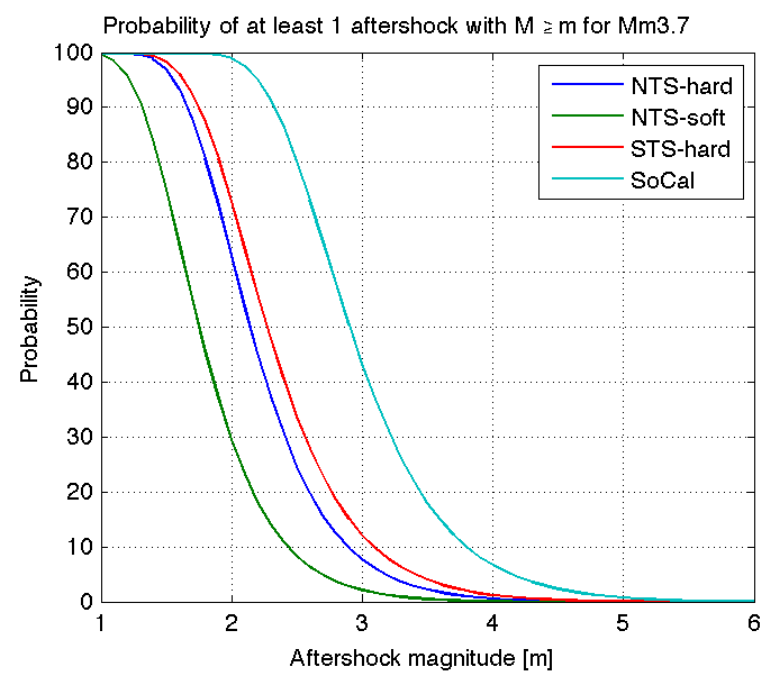

Figure 15. Probability of $\geq 1$ aftershock in 30 days for three nuclear explosion models and one earthquake model (SoCal). The NTS models predict the probability of an aftershock greater than 4 is much less than 1\%. The STS (Kazakhstan) hard rock nuclear explosion model predicts the probability of an aftershock greater than magnitude 4 is less than $1.3 \%$. This is likely an over-prediction for chemical explosions like the RV-DC as discussed in the text above and we intend to update the model in FY13.

\section{Recommendations for next steps for FY13:}

1) Given the SPE1-3 chemical explosions have not produced visible aftershocks, we believe our current model-based nuclear explosion induced seismicity rates are too high for chemical explosions. We recommend using the SPE and other explosion data to refine the probability estimate and produce an updated estimate for our best estimate of the actual RV-DC plans in 2013.

2) Because the concern about explosion-induced earthquakes may not be entirely rational, the scientific studies done to date and those proposed above may not be sufficient. If this is judged to be the case, we recommend considering convening an independent expert panel to review and examine the specific RV-DC induced seismicity concerns. Such a panel can provide the general public a greater degree of confidence that all relevant factors have been considered before the experiment proceeds. 


\section{Conclusions}

The RV-DC is designed to be the capstone of the ongoing Source Physics Experiments. This initial feasibility report shows that the RV-DC experiment has tremendous potential benefits to understanding the relationship between earthquakes and explosions, which would be exploited to improve nuclear explosion monitoring and put it on a much firmer physical basis. The RV-DC experiment also has the potential to greatly improve our understanding of earthquake physics, with possible application to improve both earthquake-explosion discrimination and perhaps earthquake hazard modeling as well.

The current schedule for the SPE makes it fairly clear that drilling for the RV-DC experiment would not happen before FY14-FY15 at the earliest, so there are at least one to two years for additional planning and preparation work. This initial feasibility work was done with very limited funding. As funding increases in FY13, we have identified in this report our recommendations for planning activities in FY13 to be carried out as part of our LCP. 


\section{References}

Brocher, T. M., (2003). Detonation charge size versus coda magnitude relations in California and Nevada, Bull Seism. Soc. Am., 92, 2089-2105.

Brune, J., (1970). Tectonic stress and the spectra from seismic shear waves earthquakes, J. Geophys. Res., 75, 4997-5009.

Denny, M.D. and L.R. Johnson (1991). The explosion seismic source function: Models and scaling laws reviewed, in Explosion Source Phenomenology, $A G U$ Monograph, 65: ed. S. Taylor et al., 1-24.

Ford, S. R. and W. R. Walter, (2010). Aftershock characteristics as a means of discriminating explosions from earthquakes, Bull. Seism. Soc. Am. 100, 364376, doi:10.1785/0120080349.

Khalturin, V. I., T. G. Rautian, and P.G. Richards, (1998). The seismic signal strength of chemical explosions, Bull. Seism. Soc. Am., 88, 1511-1524.

Mueller R.A. and J.R. Murphy (1971). Seismic characteristics of underground nuclear detonations: Part I. seismic spectrum scaling, Bull. Seism. Soc. Amer, 61, 16751692.

Myers, S.C., W.R. Walter, K. Mayeda, and L. Glenn (1999). Observations in support of Rg scattering as a source for explosion $S$ waves: regional and local recordings of the 1997 Kazakhstan depth of burial experiment, Bull. Seismol. Soc. Am., 89, 544-549.

Myers, S. C., G. Johannesson and W. Hanley, (2007). A Bayesian hierarchical method for multiple-event seismic location, Geophys. J. Int. 2007. doi: 10.1111/j.1365246X.2007.03555.X

Myers, S. C., G. Johannesson and W. Hanley, (2009). Incorporation of probabilistic seismic phase labels into a Bayesian multiple-event seismic locator, Geophys. J. Int., 177, 193-204, doi: 10.1111/j.1365-246X.2008.04070.x

Pasyanos, M.E., W.R. Walter, and E.M. Matzel (2009). A simultaneous multi-phase approach to determine P-wave and S-wave attenuation of the crust and upper mantle, Bull. Seism. Soc. Amer., 99, 3314-3325, doi:10.1785/0120090061.

Pasyanos, M.E., S. R. Ford and W. R. Walter (2012a). Testing event discrimination over broad regions using the historic Borovoye Observatory explosion dataset, Pure Appl. Geophys. Doi: 10.1007/s00024-012-0591-4.

Pasyanos, M.E., W.R. Walter, and K.M. Mayeda (2012b), Exploiting regional amplitude envelopes: a case study for earthquakes and explosions in the Korean Peninsula, Bull. Seism. Soc. Amer., (accepted May 2012 and in press).

Shields, G. (1999). Source parameter investigation of the 1993 Rock Valley earthquake sequence, Master's thesis U. Nevada-Reno, 69pp.

Smith, K. D., J. N. Brune, and G. Shields (2000). A sequence of very shallow earthquakes in the Rock Valley fault zone, southern Nevada Test Site, U.S. Geol. Open-File Rept. Seismic Hazard Issues Yucca Mountain.

von Seggern, D. H., and J. N. Brune (2000). Seismicity in the Southern Great Basin, 1868-1992, in Geologic and geophysical characterization studies of Yucca Mountain, Nevada, J. W. Whitney, and W. R. Keefer (Editors), Vol. DDS-0058, 
United States (USA).

Walter, W.R., K. Mayeda, and H.J. Patton (1995). Phase and spectral ratio discrimination between NTS earthquakes and explosions Part 1: Empirical observations, Bull. Seism. Soc. Am., 85., 1050-1067.

Walter, W. R., K. Mayeda, R. Gok and A. Hofstetter, (2006). The scaling of seismic energy with moment: simple models compared with observations, in "Earthquakes: Radiated Energy and the Physics of Faulting" American Geophysical Union Monograph 170, doi:10.1029/170GM05, 25-41. 